\title{
Rationale of Aceclofenac in Management of Pyrexia inPaediatric Practice
}

\author{
Dr AvinashShankar ${ }^{1 *}$, Dr AmreshShankar ${ }^{2}$, Dr Anuradha Shankar ${ }^{3}$ \\ ${ }^{l} M B B S(M G I M S) ; M D($ Internal Medicine);DNB(E\&M);PhD, Postgraduate in Endocrinology \& Metabolism \\ (AIIMS Delhi), Chairman, National Institute of Health \& Research, Warisaliganj (Nawada) Bihar India \\ ${ }^{2}$ BAMS(BRABU);MHA, Director (Hon), AarogyamPunarjeevan, Ram Bhawan, Ara Garden \\ Road,Jagdeopath,Baily Road, Patnal4
}

${ }^{3} B A M S$ (BRABU), Ex Director, Centre for Indigenous Medicine \& Research, Senior Research Fellow, Regional Institute of Ayurveda Itanagar, Arunachal Pradesh

\begin{abstract}
*Corresponding Author:Avinash Shankar, MBBS(MGIMS);MD(Internal Medicine);DNB(E\&M);PhD, Postgraduate in Endocrinology \& Metabolism (AIIMS Delhi), Chairman, National Institute of Health \& Research, Warisaliganj (Nawada) Bihar India
\end{abstract}

\begin{abstract}
Pyrexia, a complex physiological response triggered by infection or aseptic stimuli causes increase in Prostaglandin E2(PGE2)concentration in brain and later firing rate of neurones of thermoregulatory centre i.e. Hypothalamus.

Majority attendance at paediatrician chamber are of children with pyrexia of varied origin and to calm the temperature at optimal level various therapeutics are in vogue but attendance of children with antipyretics adversity presenting as morbidity and mortality necessitated an evaluation of presenting hazards with consuming antipyretics
\end{abstract}

Objective of Study:Analyse the rationality of Aceclofenac paracetamol combination, as antipyretics in paediatric practice.

Material and Methods: analysis of datasheet of patients admitted with antipyretics adversity at Centre for Children Disease \& Research.

Result:children consuming Aceclofenac Sodium Paracetamol presented with grave status of prolonged hypothermia, CNS disturbances like Dizziness, Convulsion,coma in addition to more pronounced other presentation like persistant vomiting, haematemesis, blood dyscariasis, rash, albuminuria than other.

Conclusion:Acceclofenac sodium Paracetamol combination must be restricted for paediatrics use considering its dreaded outcome.

Keywords:Pyrexia, Prostaglandin, hypothalamus, thermoregulatory, CNS disturbances hypothermia, blood dyscariasis, albuminuria

\section{INTRODUCTION}

Pyrexia,a common clinical presentation of varied clinical conditions estimating 1/3 of all children visit to health care centre and parent usually self medicate their children with the over the counter (OTC) antipyretics . ${ }^{1,2}$

Fever is a beneficial outcome of the physiologic response triggered by infection or aseptic stimuli as it boost immunity against the invading pathogen,though beyond certain level it may cause discomfort and organic damage which usually presents with febrile convulsion ${ }^{3,4}$

Fever up to $102^{\circ} \mathrm{F}$ is considered beneficial but $>102^{\circ} \mathrm{F}$ become harmful and disastrous thus medication needed to keep the temperature $<102^{0} \mathrm{~F}^{5,6}$ 


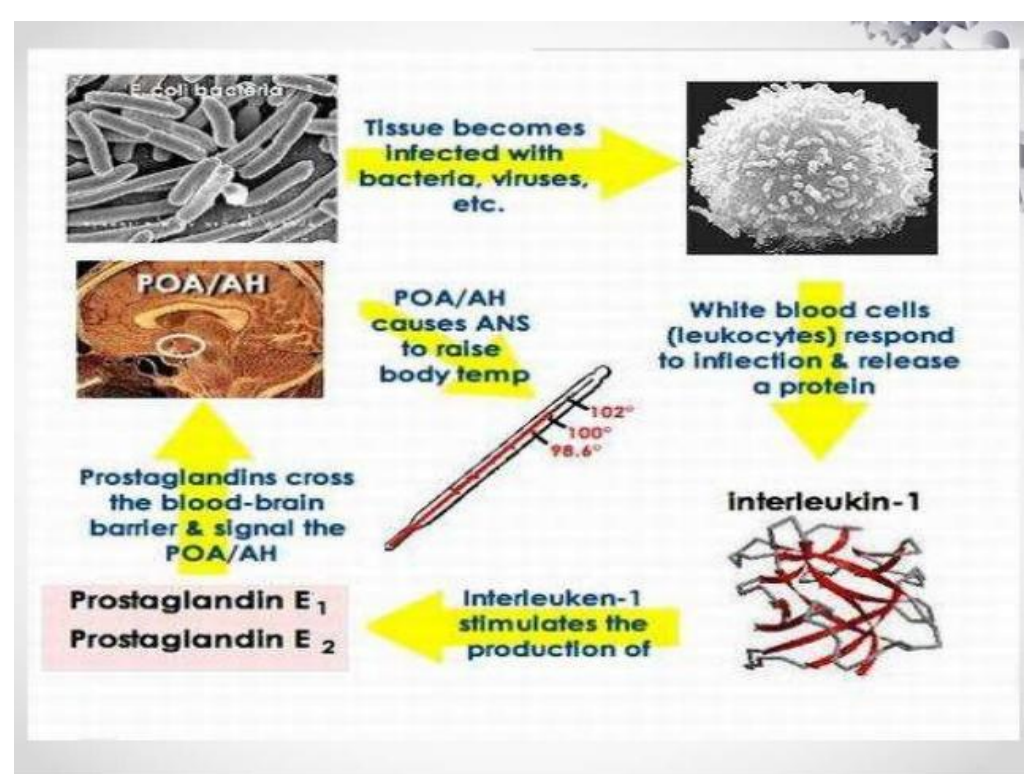

Figure1.Schematic presentation of Fever generation

Fever result from an immune response mediated through the action of cytokinin on thermoregulatory centre of the brain Or by conserving heat through vaso- constriction manifesting as Chills Or generating heat by active muscular contraction i.e.- rigor (Figure -2)

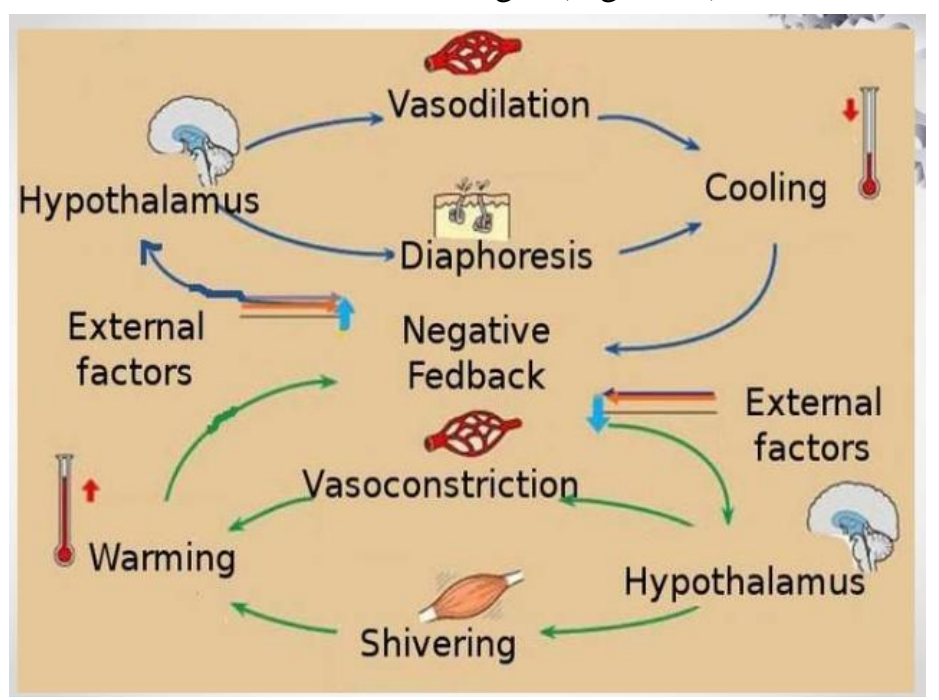

Figure2. Schematic representation of Thermal haemostasis

During fever in addition to specific therapeutics the molecules usually prescribed is antipyretics and the commonly prescribed are - Paracetamol (Acetaminophen); Mefenamic acid,Ibuprofen and Nimesulide either alone or in combination with paracetamol,but these days Aceclofenac and paracetamol being commonly prescribed and sold as over the counter antipyretics in children ${ }^{7,8,9,10}$

Fever may be suppressed by antipyretic or by physical cooling. During antipyretics prescription safety profile must be choice as majority of antipyretic are equally effective and their proper dose and administer schedule must be ensured.$^{11,12}$

Most antipyretics act by inhibiting the enzyme Cyclooxygease and reduces PGE2 within the hypothalamus but may be due to reduction of pro inflammatory mediator,increased anti inflammatory signals or boost antipyretic message within the brain ${ }^{.13,14}$

Usually village practitioner follow the prescription of qualified clinician and over the counter drugs are being used only when manufacturer come with these products with due permission from FDA. Availability of Aceclofenacsodium-paracetamol suspension being rampantly used for pyrexia in children.

As drug formulation approval is the responsibility of FDA,this study is being conducted with an intent to asses the rationality of Suspension Aceclofenac with paracetamol as an antipyretic for children. 


\section{OBJECTIVE OF THE STUDY}

Analysis of untoward effects observed in children taking Aceclofenac -Paracetamol combination for treatment of fever

\section{DURATION OF STUDY}

Patients attended the centre between January 2016- February 2018

\section{MATERial \& MethodS}

\subsection{Material}

Children suffering with pyrexia and consumed Aceclofenacsodium-paracetamol combination and admitted at Centre For Research in Children Disease,RA. Hospital \& Research Centre,Warisaliganj (Nawada) Bihar with unusual presentation been selected for analysis.

\subsection{Method}

Patient's parent or attendant were interrogated for therapeutics taken,its dose administration and appearance of the manifestation,clinically examined and investigated for haematological,hepatic and renal profile.

Patients presenting with hypothermia,perspiration,hypotension,cardiac dysrhythmia unconsciousness and convulsion were treated accordingly

\section{OBSERVATIONS}

Children consuming various antipyretics for relief of fever and attending at Centre for Children Disease Research were of age group <1->5 yrs majority 614 (22.7\%) patients of age group 4-5 years.(Table-1)

Table1.Age \& sex wise distribution of patients

\begin{tabular}{|l|l|l|l|l|}
\hline Age Group (in years) & \multicolumn{5}{|c|}{ Number of Patients } \\
\hline & Male & Female & Total & $\%$ \\
\hline$<1$ & 138 & 94 & 232 & 8.6 \\
\hline $1-2$ & 238 & 142 & 380 & \\
\hline $2-3$ & 312 & 212 & 524 & \\
\hline $3-4$ & 308 & 202 & 510 & \\
\hline $4-5$ & 406 & 208 & 614 & \\
\hline$>5$ & 298 & 146 & 444 & \\
\hline
\end{tabular}

Out of all 1700 were male and 1000 female (Figure-3)

Pie diagram showing Male Female Composition

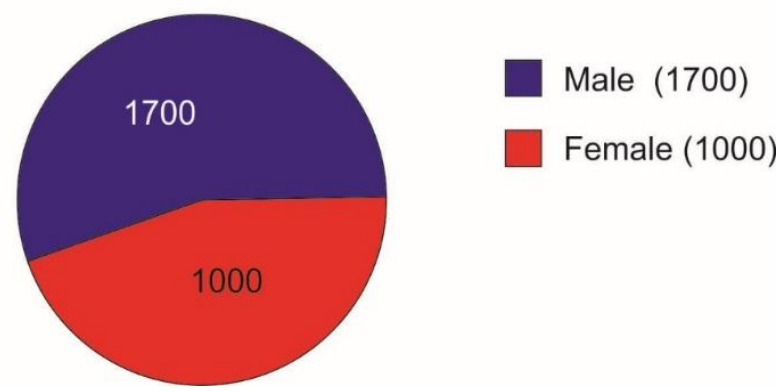

Figure3

Out of all $25 \%$ were taking Aceclofenac -paracetamol while $4.2 \%$ only paracetamol though $34 \%$ patients were taking Nimesulide\&paracetamol (Table-2)

Table2. Distribution of patients as per their therapeutics

\begin{tabular}{|l|l|l|}
\hline Therapeutic group & Number of Patients & $\%$ \\
\hline Acceclofenac sodium + Paracetamol & 674 & 25 \\
\hline Nimesulide +Paracetamol & 924 & 34 \\
\hline Ibuprofen +Paracetamol & 474 & 17.5 \\
\hline Mefinamic acid +Paracetamol & 322 & 12.0 \\
\hline Nimesulide & 208 & 7.3 \\
\hline Paracetamol & 98 & 4.2 \\
\hline
\end{tabular}


Though nausea remain a common manifestation among all patients of varied therapeutic group,but manifestation like Dizziness,rash,GI bleeding,blood dyscariasis,convulsion,prolonged hypothermia remain more pronounced with marked albuminuria in patients taking Aceclofenac sodium Paracetamol combination. Patients taking Aceclofenac paracetamol presenting with adversity like Dizziness,convulsion and sustained hypothermia resulted in un eventful fate i.e. mortality in 20 cases out of 674 but non of other group.(Table -3)

Table3. Presentation observed during therapy

\begin{tabular}{|c|c|c|c|c|c|c|}
\hline Presentations & \multicolumn{6}{|c|}{ Number of cases in various group of terapy } \\
\hline & AP & NP & IP & MP & $\mathrm{N}$ & $\mathrm{P}$ \\
\hline & $(674)$ & $(925)$ & $(474)$ & $(322)$ & $(208)$ & $(98)$ \\
\hline Nausea & 425 & 306 & 138 & 102 & 50 & 06 \\
\hline Vomiting & 288 & 103 & 60 & 32 & - & - \\
\hline Dyspepsia & 300 & 108 & 68 & 40 & - & - \\
\hline Abdominal colic & 342 & 110 & 92 & 46 & - & - \\
\hline Dizziness & 208 & - & - & - & - & - \\
\hline Rash & 196 & - & - & - & - & - \\
\hline GI bleeding & 12 & - & - & - & - & - \\
\hline Blood dyscariasis & 37 & - & - & - & - & - \\
\hline Convulsion & 19 & - & - & - & - & - \\
\hline $\begin{array}{l}\text { Prolonged } \\
\text { hypothermia }\end{array}$ & 78 & - & - & - & - & - \\
\hline
\end{tabular}

(Key: AP:Aceclofenac Sodium -Paracetamol,NP:Nimesulide-ParacetamolIP: Ibuprofen -Paracetamol;MP: Mefenamic acid-paracetamol;N: NimesulideP: Paracetamol)

Onset of antipyretic effect was similar in all the groups sustained prolonged hypothermia was very common in patients consuming Aceclofenac sodium - Paracetamol than Nimesulide -paracetamol (Figure -4)

Group Showing Antipyretic effect of various combinations

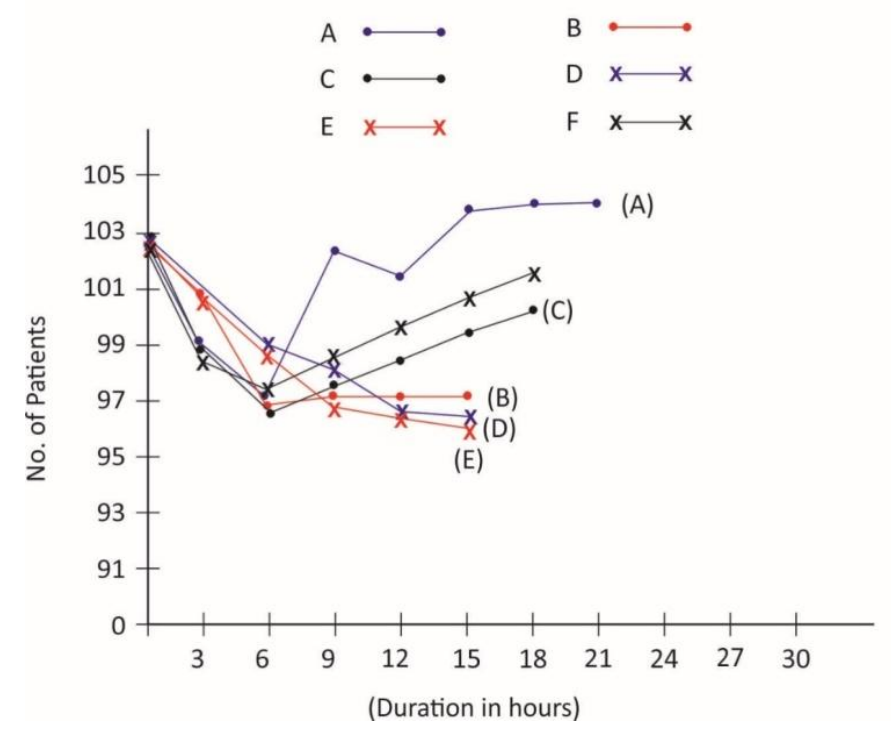

Figure4

\section{RESULT}

Antipyretic available shows equianti pyretic effect for varied duration. Patients taking AcceclofenacParacetamol combination shows highest drug adversity in children than other anti pyretics, with dreaded toxicity like prolonged and sustained hypothermia resulting in morbidity and mortality, thus must be restricted its use as antipyretics.

\section{CONCLUSION}

Considering the untoward effects causing morbidity and mortalitywith Aceclofenac Sodium Paracetamol,its advocation in children must be restricted 


\section{DISCUSSION}

Pyrexia remain a major cause of children attendance at Clinician chamber and majority comes with use of various over the counter antipyretics Or treated by local practitioners. As to calm the fever use of antipyretic is an Ernest need but must be used with due caution as -Evaluation of data sheet of children presenting with fever of varied origin taking various antipyretic and presenting with sequel suggest pronounced drug adversity with Acceclofenac sodium -paracetamol combination than other i.e.- dizziness,rash, blood dyskaryosis,marked albuminuria,convulsion,sustained and prolonged hypothermia resulting in brain death.

Most antipyretics act by inhibiting the enzyme Cyclo oxygenase and reducing the level of PGE2 within the hypothalamus, but may be due to reduction of pro inflammatory mediators, increase antiinflammatory signals Or boost anti pyretic messages within the brain (Figure 5).

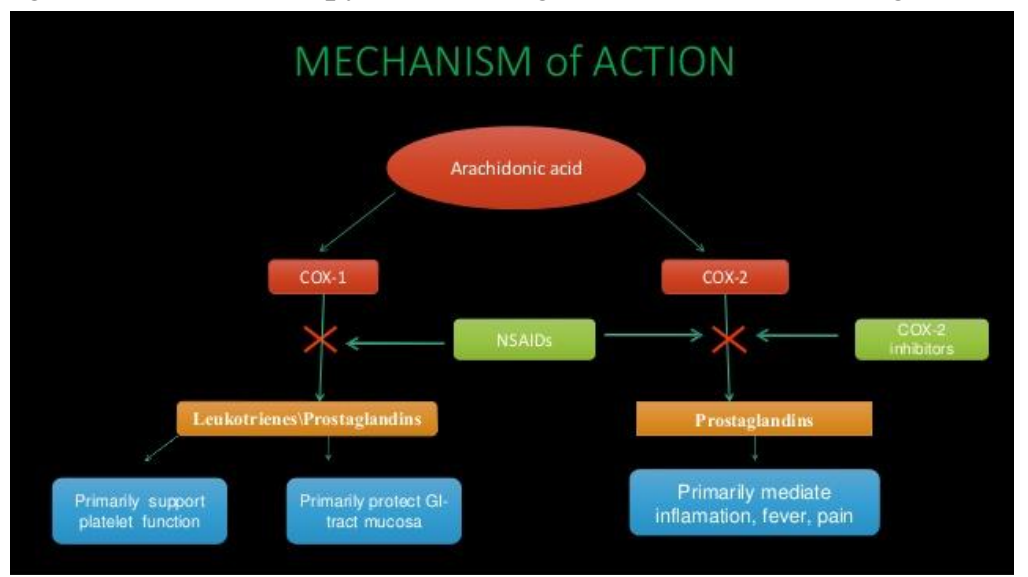

Figure5. Schematic presentation of Antipyretic action

Aceclofenac sodium is an orally effective nonsteroidalanti inflammatory drug of phenyl acetic acid group possessing remarkable anti inflammatory,analgesic and antipyretic properties but usually a choice prescription for rheumatoid arthritis,osteoarthritis and ankylosing spondylitis,but not recommended in children. Aceclofenac shows more selective effect towards COX2 than COX 1 and inhibits synthesis of Prostaglandin (PGE2), a product of inflammatory cytokine,interleukin and tumour necrosis factor, in addition also affect cell adhesion molecules from neutrophil.15,16

This also interrupts the endo cannabinoid system and endocannabinoid 17,18 as COX2 utilises endo cannabinoid as a substrate and plays key role in producing drug adversity specially in children,pregnant and breast feeding mother. (Figure 6)

\begin{tabular}{|lr|}
\hline ANTIPYRETICS & ACETAMINOPHEN \\
NSAID & (Potent antipyretic) \\
(Selective Cox 2 inhibitor) & \\
Aceclofenac Sodium & \\
(Potent analgesic, anti inflammatory & \\
\&anti arthritic) & \\
& \\
Increases Canabinoid secretion & Prologed Hypothermia \\
Increased Endorphin & Brain Dysfunction \\
Suppress CNS function & \\
Dizziness & \\
Convulsion & \\
ComaComa & \\
DEATH & \\
(Schematic presentation of AceclofenacParacetamol adversity)
\end{tabular}

Figure6. Schematic presentation of Aceclofenac_paracetamol adversity) 


\section{REFERENCES}

[1] May A, BauchnerH, Fever phobic the paediatrician's contribution Paediatrics 1992:90:851-854(pubmed)

[2] May A, Bauchner H. Fever phobia: the pediatrician'scontribution. Pediatrics. 1992;90:851-854.[PubMed]

[3] El-Radhi AS, Carroll J. Fever in paediatric practice. Oxford: Blackwell Scientific Publications; 1994. p. 243.

[4] Solomon HC, Kopp I. Fever therapy. N Engl J Med. 1937;217:805-814.

[5] Pearce C, Curtis N. Fever in children. Aust Fam Pract 2005; 34: 769-771Google Scholar.

[6] Gurer US, Palanduz A, Gurbuz B, Yildirmak Y, Cevikbas A, Kanyaalp N. Effect of antipyretics on polymorphonuclear leukocyte functions in children. IntImmunopharmacol 2002; 1599-1602

[7] Walsh A, Edwards H, Fraser J. Over-the-counter medication use for childhood fever: a cross-sectional study of Australian parents. J Paediatr Child Health. 2007;43:601-606. [PubMed]

[8] Goldman RD, Ko K, Linett LJ, Scolnik D. Antipyretic efficacy and safety of ibuprofen and acetaminophen in children. Ann Pharmacother. 2004;38:146-150. [PubMed]

[9] Li SF, Lacher B, Crain EF. Acetaminophen and ibuprofen dosing by parents. PediatrEmerg Care. 2000;16:394-397. [PubMed]

[10] Wright AD, Liebelt EL. Alternating antipyretics for fever reduction in children: an unfounded practice passed down to parents from pediatricians. ClinPediatr (Phila) 2007;46:146-150. [PubMed]

[11] Mayoral CE, Marino RV, Rosenfeld W, et al. Alternating antipyretics: is this an alternative? Pediatrics 2000; 105: 1009-1012PubMedCrossRefGoogle Scholar.

[12] Goldman RD, K0 K, Linett LJ, et al. Antipyretic efficacy and safety of ibuprofen and acetaminophen in children. Ann Pharmacother 2004; 38(1): 146-150PubMedCrossRefGoogle Scholar

[13] Wright AD, Liebelt EL. Alternating antipyretics for fever reduction in children: an unfounded practice passed down to parents from pediatricians. ClinPediatr 2007; 46: 146-150CrossRefGoogle Scholar.

[14] Ngong JM, Waring RH. Circadian rhythms of paracetamol metabolism in healthy subjects: A preliminary report. Chronobiology Drug Metabol Drug Interact 1994; 11: 317-330.

[15] Shankar A etal ; comparative evaluation of antipyretic effect of Nimesulide versus Ibuprofen, Mefenamic acid and Paracetamol in pediatric practice ,The Antiseptic , Vol 96;No 12: 457-459:1999

[16] McCarthy PL (Ed). Fevers and the Evaluation of the Child with who has Fever. Philadelphia: Saunders, 1999. pp. 157-163

[17] Grau M, Guasch J, Montero JL, et al. Pharmacology of the potent new non-steroidal anti-inflammatory agent aceclofenac. ArzneimittelForschung 1991 Dec; 41: 1265-76PubMedGoogle Scholar

[18] Grau M, Montero JL, Guasch J, et al. The pharmacological profile of aceclofenac, a new nonsteroidal antiinflammatory and analgesic drug. Agents Actions 1991; 32 Suppl.: 125-9CrossRefGoogle Scholar

Citation: Dr Avinash Shankaret al. "Rationale of Aceclofenac in Management of Pyrexia in Paediatric Practice ", International Journal of Clinical Chemistry and Laboratory Medicine (IJCCLM), vol. 5, no. 1, pp. 1-6, 2019.http://dx.doi.org/10. 20431/2455-7153.0505001

Copyright:(C) 2019 Authors. This is an open-access article distributed under the terms of the Creative Commons Attribution License, which permits unrestricted use, distribution, and reproduction in any medium, provided the original author and source are credited. 